\title{
LLAMADO A LA VOCACIÓN: SAN AGUSTÍN
}

\author{
Sem. Juan Carlos Encina
}

\section{Introducción}

No resulta tarea sencilla, escribir sobre un hombre que no escribió cientos de obras, sino que sus obras superan el número mil.

Tal es el caso de Aurelius Augustinus, más conocido como San Agustín.

Aurelius Agustinus (Aurelio Agustín), nació el 13 de Noviembre del año 354 en Tagaste, pueblecito de Numidia, en el África, hoy Argelia. Murió en Hipona el 28 de Agosto del año 430.

Sus padres Fueron Patricio y Mónica; él pagano, ella ferviente cristiana. Tenía un hermano llamado Navigio y una hermana llamada Perpetua.

En este pequeño trabajo nos dedicaremos al llamado de su vocación, que como veremos en breve no fue «uno» sino varios, y claro está que acá no abarcamos todos esos llamados.

En este resumen muy escueto de su conversión podemos ver con total nitidez la veracidad de aquella parábola de Nuestro Señor Jesucristo cuando comparó al Reino de los Cielos con una semilla de mostaza, que es la mas pequeña de todas las semillas. Pero una vez sembrada, crece, y en sus ramas hasta las aves del cielo hacen nidos (Mc 4, 30-32).

Se puede apreciar con claridad como la semilla del Cristianismo es plantada en el corazón de Agustín y que, a pesar de tardar en crecer, una vez que dio frutos no solo las aves de aquella época en la que vivió nuestro Santo hicieron nidos en sus ramas, ya que aún hoy seguimos haciendo moradas en su inmenso follaje.

\section{Primeros Contactos de Agustín con el Cristianismo}

Su madre Mónica, una cristiana fervorosa, que no temía hacer uso de la autorización oficial para practicar la fe en Cristo a partir del Edicto de Milán (año 313), fue quien desde temprana edad ejerció en su hijo una enorme influencia y 
lo educó en la Fe. Podemos ver que a pesar de tener contacto directo con la Fe Cristiana, desde temprana edad, Agustín no se sintió llamado por Dios, y no sucederá si no hasta muchos años más tarde

Como dijo Benedicto XVI en una audiencia general en enero del 2008:

San Agustín siempre quedó fascinado por la figura de Jesucristo, pero se alejó cada vez más de la fe eclesial, de la práctica eclesial (Benedicto XVI, Audiencia General 9 de enero de 2008, 2008).

\section{Primer llamado a la vocación}

La educación del siglo IV se comprendía de 3 Grados a saber: $1^{\circ}$ Grado hasta los 12 años donde la formación básica era aprender a leer, escribir y contar. El $2^{\circ}$ Grado de los 12 a los 16 años, se aprendía lengua latina, gramática y se debía leer y analizar a los historiadores y poetas. Y el $3^{\circ}$ de los 16 a los 20, se completaba con estudios de retórica y filosofía.

Nuestro adolescente Agustín, luego de terminados sus estudios de $2^{\circ}$ Grado o estudios medios, para finalizar sus estudios ( $3^{\circ} \mathrm{Grado}$ ), es enviado a Cartago para cursar la elocuencia, que en esa época era el mejor camino a la fortuna y la gloria. En otras palabras se cultivaba el arte del bien decir, y Agustín se hallaba dotado de maravillosas disposiciones para esta profesión.

Llegado a Cartago nuestro adolecente cae, según sus propias palabras, en:

Una caldera hirviente de amores pecaminosos" (Agustín, 2017, 3, 1), "mi alma, enferma y ulcerosa, se proyectaba hacia afuera, ávida del halago de las cosas sensibles (Agustín, 2017, 3, 2).

Se apasionó además por los espectáculos teatrales de la época.

Justamente los estudios emprendidos por Agustín lo encaminaban a las actividades del foro y sus litigios. Y según nos cuenta el propio Agustín:

Yo era el mayor en la escuela de retórica, era soberbio y petulante tenía la cabeza llena de humo (Agustín, 2017, 3, 3).

Así se hallaba Agustín, quien, desde este punto de vista, pareciera ser bastante difícil que en tales condiciones pueda recibir un llamado de Dios. Pero los caminos del Señor son insondables. Veamos que le sucede a nuestro adolescente; en estos momentos de su vida, «muy lejos de llamarse "San" Agustín».

En medio de tales circunstancias y compañías y siguiendo el curso normal de sus estudios, se topa con una obra de Cicerón titulada Hortensio, en esta obra se exhortaba a no seguir 


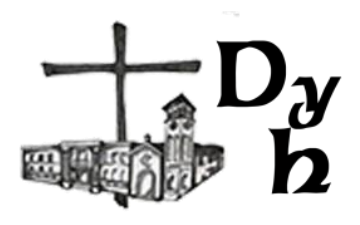

Esta secta o la otra, sino a la sabiduría misma, cualquiera que ella fuese, que había que buscarla y una vez conseguida abrazarse a ella con todas las fuerzas (Agustín, 2017, 3, 4).

Este texto encendió en el corazón de Agustín un increíble ardor por encontrar esa sabiduría inmortal. Esto sucedió a los 19 años. Nos dice Agustín que, a partir de ese momento, cambiaron sus sentimientos y se mudaron todos sus anhelos. Podemos ver que Agustín buscaba esa sabiduría, la buscaba con verdadera intención. Claro que en este momento nuestro soberbio joven ni siquiera se imaginaba que emprendería una búsqueda nada más y nada menos que de Dios mismo. Ya que en Dios reside toda sabiduría y prudencia. "¡A Dios, el único sabio, por medio de Cristo Jesús, a él sea la gloria por siempre!" (Rom $16,27)$

Ignorando esta realidad por completo, Agustín decide "leer las sagradas escrituras para ver cómo eran". Pues, a nuestro vanidoso muchacho, no le pareció nada interesante y hasta las encuentra indignas en su lenguaje comparado con la dignidad del de Cicerón.

Haciendo un paréntesis en su historia, podemos ver aquí el claro llamado del Señor al hacer arder el corazón de Agustín cuando se inicia en la empresa de llegar a esa sabiduría inmortal, pero claro está que no se encontraba preparado para recibirla y abrazarla. De este primer llamado podemos decir que se plantó la semilla pero que no daría sus brotes si no más adelante.

Tal como nos dice el escritor Francisco Ugarte Corcuera:

La vocación es, radicalmente, una llamada de Dios al hombre concreto, quien debe tomar una decisión ante esa llamada (Ugarte, 2014, pág. 15).

Demás está decir que no fue aceptada en esta oportunidad por Agustín.

\section{Segundo llamado a la vocación}

Siguiendo con la decisión de alcanzar la sabiduría, Agustín en esos momentos de su vida "hinchado de vanidad se sentía muy grande" (Agustín, $2017,3,5)$. Es así que cae en la red de los maniqueos, quienes se presentaban como cristianos y ofrecían una religión totalmente racional, pero, en realidad, eran hombres de una soberbia delirante y muy carnales (Agustín, 2017, 3, 6). Ser miembro de esta religión ofrecía varias ventajas entre las que se cuenta la apertura de fáciles perspectivas para su carrera, contar con los contactos de personalidades influyentes y progresar, además de la posibilidad de mantener una relación con una mujer. Esto duraría 9 años, desde sus 19 hasta los 28 años, periodo en el cual era seducido y seductor, engañado y engañador.

Aquí comienza otra de las formas del llamado a la vocación, ya que empieza a sentirse inquieto con la enseñanza de los maniqueos, que lo fueron 
decepcionando precisamente desde el punto de vista intelectual, pues no le cerraban sus respuesta con respecto a varios puntos de doctrinas.

Esto es coincidente con las señales de la vocación o llamado de Dios. Recordemos que Agustín perseguía la sabiduría inmortal y comenzaba a darse cuenta de que las enseñanzas de los maniqueos eran incompletas y contradictorias. Comienza a sentir esa insatisfacción, ese vacío que dejan ciertas actividades humanas y los bienes temporales (Ugarte, 2014, pág. 41).

\section{Tercer llamado a la vocación}

Alrededor de sus 28 años comienza a enseñar en el municipio donde nació. Aquí vuelve a entablar relación con un amigo con quien, nos dice el propio Agustín, se conocían de niños y adolescentes, pero no llegaron a ser verdaderamente amigos como en esta oportunidad, que fue una amistad dulcísima, al decir de sus Confesiones. A tal grado que Agustín dice que no podía vivir sin él, confiesa también que él mismo lo desvió de su fe, haciendo aquellas supersticiosas fábulas por la que su madre les lloraba no hacer. Pero apenas cumplido un año de esta amistad su amigo cae enfermo y quedó inconsciente por un tiempo. Los familiares, temiendo por su vida, lo bautizan mientras estaba inconsciente, pero Agustín no se preocupó en lo más mínimo por este bautismo, ya que según sus ideas en ese momento, el alma de su amigo habría de retener más bien lo que aprendió de él que de cualquier otra persona. Luego de este bautismo su amigo se recuperó. Con el primero que habla es con Agustín, pues éste no se separaba de su amigo, ya que dependían fuertemente uno del otro. Lo primero que Agustín le cuenta es sobre su bautismo y comienza a ridiculizarlo ya que se había hecho con total ausencia de sí mismo. Para sorpresa de Agustín, su amigo lo mira con horror como a un enemigo y con libertad tan admirable y repentina declaró que si quería seguir siendo su amigo "debía renunciar a hablar de semejante modo". Agustín, en ese momento estupefacto con tal respuesta, decide esperar a que esté mejor para poder hablarle a su amigo como "él quería". Más tarde su amigo recae y muere, Agustín entra en una profunda depresión que no sería superada sino tiempo más tarde.

Nuevamente vemos aquí el llamado de Dios, esta vez a través de una persona, otro de los métodos de Dios para comunicar o trasmitir el llamado. Como nos dice Francisco Ugarte:

No es de extrañar que Jesús siga contando con la mediación de instrumentos como un director espiritual, un amigo, el amigo que hace apostolado con el amigo, etc. (Ugarte, 2014, pág. 29)

Esto es reconocido por Agustín tiempo después cuando con sus propias palabras dice: "pero Tú lo arrebataste de mi demencia para conservarlo en ti". 


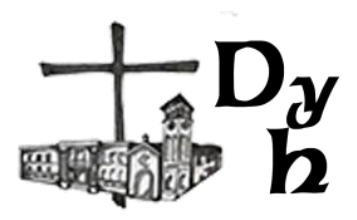

\section{Cuarto llamado a la vocación}

Para este cuarto llamado nos situamos en Roma. Agustín, en busca de mejores condiciones laborales y con la intención de establecer una escuela de retórica en el lugar, se traslada a Roma. Una vez allí un hombre llamado Símaco, prefecto de Roma, recibe una solicitud de Milán para que enviara allá un maestro de retórica y se ofrecía a costa del erario público todo cuanto necesitara para su traslado. Agustín se las arregló una vez más para conseguir el puesto (Agustín, 2017, 5, 13). Enviado a Milán, es recibido nada más y nada menos que por el Obispo Ambrosio, quien ya era renombrado en todo el orbe por sus óptimas cualidades. Aun así, recordemos que, si bien Agustín seguía en la búsqueda de la sabiduría inmortal, no era una persona fácilmente influenciable, por lo que, al principio, el Obispo Ambrosio solo le pareció una persona amable.

Aquí comenzó a escuchar los discursos del Obispo con mucha atención. Primero no se interesó mucho por el contenido, sino por la suavidad de su palabra. Luego comenzó a analizar el contenido, que no tenía comparación con lo enseñado por los maniqueos. Ambrosio hablaba de salvación de una manera muy saludable. Sin embargo a pesar de que Agustín tratara de hacer a un lado el contenido del discurso y solo prestar atención a cómo lo decía, comenzó a resonar en su alma, ya que llegaba a él envuelto en bellas palabras y por esto no podía disociarlo.

Todavía en esta instancia, Agustín nos dice con respecto a la fe católica que hasta ese momento pensaba que no podía defenderse de las objeciones de los maniqueos. Pero al escuchar los discursos de Ambrosio este pensamiento comenzó a decaer.

Aquí podemos ver varios medios de los que el Señor se vale para realizar sus designios. Primero la llegada de Agustín a Roma, luego atrayéndolo a Milán. Segundo, la presencia de San Ambrosio y sus discursos u homilías. Tercero, la acción propia del espíritu del Santo sobre Agustín haciéndole comprender su palabra. Se cumple aquí lo dicho por el Apóstol Pablo que la palabra es "portadora de su gracia, que tiene eficacia para edificar a las personas y entregarles la herencia junto a todos los santos" (Hch 20, 32).

Sin saberlo, Agustín se encontraba en presencia de la Palabra edificante de Dios; a partir de este momento todo solo será cuestión de tiempo.

En conclusión, este cuarto llamado es a través de un siervo del Señor y la Palabra misma de Nuestro Señor, es decir, las Sagradas Escrituras. 


\section{Quinto llamado a la vocación}

Luego de estas experiencias con Ambrosio y sus discursos, si pensamos que Agustín habría realizado un cambio en su vida de manera inmediata, todavía estamos distantes.

La semilla que fue plantada en su primer llamado con aquella lectura de la obra de Cicerón ya comenzaba a crecer. Lo deducimos fácilmente escuchando estas palabras de Agustín, por este entonces ya un hombre maduro de 30 años, "me gustaba el Salvador como camino a la vida, pero me sentía desanimado por la angostura del camino".

Agustín reconoce además que en este tiempo se encontraba hastiado de sus ocupaciones mundanas y que se volvieron extremadamente pesadas para él ya que su ambición por la gloria y el dinero había dejado de agradarle.

Tal es así que decide buscar ayuda. En esta oportunidad se entrevista con un hombre llamado Simpliciano se nos dice el mismo Agustín que fue padre en la Fe y Gracia de San Ambrosio.

Simpliciano le cuenta sobre la conversión de un famoso retórico de Roma llamado Victorino, de quien Agustín conocía su reputación, ya que él mismo había leído libros de Platón traducidos al latín por Victorino (Agustín, 2017, 8, 2).

Victorino era un anciano doctísimo y muy entendido en las artes liberales, era maestro de muchos senadores y lo tenían en tan alta estima que habían erigido en su honor una estatua suya en el foro romano.

Simpliciano cuenta a Agustín que Victorino en busca de la verdad había examinado las Sagradas Escrituras buscando comprenderlas a fondo. Según Simpliciano, Victorino le confesaba en la intimidad a Simpliciano que ya era cristiano, a lo que éste respondía que le creería cuando lo viera en la Iglesia, ya que en esos momentos Victorino temía ofender a sus orgullosos adoradores de ídolos.

Pero Victorino, tras mucho leer, comenzó a temer que Cristo lo negara delante de sus Ángeles. Tal es el caso que en el momento menos pensado le dice a Simpliciano: "vamos a la Iglesia, quiero hacerme cristiano". A Victorino se le ofrece la oportunidad de recitar la confesión de Fe de manera privada, pero éste siendo maestro de retórica decide hacerlo en público ante la presencia de todo el pueblo, haciendo su confesión de Fe con toda serenidad y pleno dominio de sí mismo. El pueblo estalló en fervorosa ovación.

Agustín nos cuenta que luego de escuchar esta conversón de Victorino su corazón suspiraba por tener una fortaleza semejante.

Nuevamente podemos ver los instrumentos en las manos de Dios para llamar a Agustín. En este caso otro siervo de Dios (Simpliciano) y por otro lado una de las más grades herramientas del llamado, no solo individual, sino también colectivo: esta herramienta es el testimonio. Pues el testimonio de 


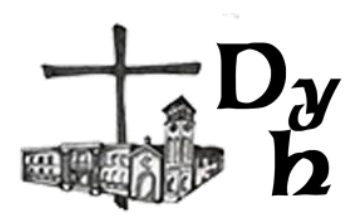

Victorino es el que acentúa con fuerza el deseo en Agustín de hacer lo mismo. Se cumple una vez más lo dicho por el apóstol Juan: "Ellos lo vencieron con la sangre del Cordero, con su palabra y con su testimonio, pues hablaron sin tener miedo a la muerte" (Ap 12, 11).

\section{Su conversión definitiva}

A estas alturas de su investigación sobre esa sabiduría inmortal, ya comprendía plenamente que se hallaba únicamente en Jesucristo, en las Escrituras, en su Iglesia. En su autobiografía Confesiones nos dice que "iba viviendo su vida con una creciente ansiedad, $y$, en medio de ella, suspiraba por Dios".

El Señor en esta oportunidad se vale de otro siervo suyo, esta vez no fue buscado por Agustín como cuando buscó a Simpliciano, éste siervo llega a casa de Agustín y de su amigo Alipio, con quien compartía la vivienda.

El nombre de este siervo es Ponticiano. Este hombre, luego de observar que Agustín tenía sobre su escritorio las cartas del Apóstol Pablo, entabla conversación con él y le cuenta sobre la conversión de un amigo suyo y cómo decide éste llevar una vida monástica. Parte del relato dice que su amigo, de quien no tenemos nombre, se encuentra con unos escritos de Antonio (San Antonio), y al leerlos se pregunta:

¿A dónde podemos llegar con todos nuestros trabajos?, ¿Podemos aspirar a algo más en el palacio que ser amigos del emperador?, ¿Y por cuánto tiempo puede durar esto?" y con el texto aún en manos se responde: "En cambio, en este mismo momento, puedo ser amigo de Dios, si así lo quiero (Agustín, 2017, $8,6)$

Esta fue la estocada final para Agustín.

Nos cuenta él mismo que, mientras escuchaba a Ponticiano, el Señor lo hacía retorcerse por dentro, que se sentía confundido y aplastado por una vergüenza profunda y horrible a medida que escuchaba el relato.

En medio de aquel verdadero combate espiritual, luego de que ya se había retirado Ponticiano, Agustín exclama a su amigo Alipio:

¿Te das cuenta cabal de lo que hemos oído? ¿Cómo dejamos que los que nada saben se encaminen y consigan el Cielo por la fuerza, mientras nosotros, con toda nuestra ciencia, languidecemos atrás, cobardes e insensibles, empantanados en nuestros pecados? (Agustín, 2017, 8, 12)

Agustín se aleja a un jardín de su casa y, amargado por el reconocimiento de sus muchos pecados, mientras se encontraba en semejante desolación oye la voz de un niño que desde la casa de una vecina repetía cantando "toma y lee, toma y lee". Entonces volviéndose a su mesa donde se encontraba los libros del Apóstol Pablo lo abrió y leyó en silencio la Carta a los Romanos donde dice: 
Basta de excesos en la comida y en la bebida, basta de lujuria y libertinajes, no más peleas ni envidias. Por el contrario, revístanse de nuestro Señor Jesucristo y no se preocupen por satisfacer los deseos de la carne (Rom 13, 13-14).

Al leer esta última parte nos dice Agustín que una luz segurísima penetró su corazón disipando de golpe las tinieblas de sus dudas, cerró el libro y marcó ese pasaje.

Y acompañado de su amigo Alipio fue enseguida a contarle a su madre.

Nuevamente, un siervo, contando la conversión de otro, los escritos de Pablo, el tener que reconocer con toda sinceridad sus pecados, la voz del niño desde la casa vecina, la búsqueda emprendida desde los 19 años de esa sabiduría inmortal, sus experiencias de vida, todo absolutamente todo converge en este momento en la vida de quien sería conocido desde este momento ahora sí- como SAN AGUSTíN.

\section{Bibliografía}

Agustín, S. (2017). Las Confesiones. Lumen.

Benedicto XVI. (2008). Audiencia General 9 de enero de 2008.

http://w2.vatican.va/content/benedict-

xvi/es/audiences/2008/documents/hf_ben-xvi_aud_20080109.html.

Ugarte, F. (2014). ¿Puedo elegir mi vocación? Logos. 